\title{
The BULLETIN of the Australian Mathematical Society
}

The BULLETIN began publication in 1969. Two volumes of three numbers each are published annually, at an annual subscription of $\$ 15$. Subscription orders and orders for back numbers should be sent to the Business Manager (address inside front cover). Manuscripts for publication should be sent to the Editor:

Professor B. H. Neumann,

Department of Mathematics,

Institute of Advanced Studies,

Australian National University,

POB 4, Canberra, ACT 2600, Australia,

or to the Associate Editor, Dr L. G. Kovács, at the same address. Authors should keep a complete copy of their manuscripts, because manuscripts are not normally returned to them.

Authors receive 50 free offprints of their papers and may order more at cost. Correspondence about proofs ąnd offprint orders should be addressed to the Assistant Editor:

Associate Professor A. McMullen,

Department of Mathematics,

Royal Military College,

Duntroon, ACT 2600, Australia.

\section{Editorial Policy}

The BULLETIN of the Australian Mathematical Society aims at quick publication of original research in all branches of Mathematics. Only manuscripts that are suitable for quick publication will be accepted, and only if space permits. Manuscripts must be in their final, publishable form when submitted; refereeing will be kept to a minimum, and no revision of manuscripts will be allowed.

The BULLETIN is printed by a photo-offset process from a carefully prepared typescript. The type founts and special symbols available are, accordingly, restricted.

To facilitate the work of reviewing journals and the Mathematical Offprint Service (MOS) of the American Mathematical Society, the BULLETIN publishes an abstract at the head of each paper that is not itself an abstract, and also a tentative MOS classification in the top right-hand corner of the first page of each paper. Authors are invited to assist by supplying abstracts of their papers and supplying or checking MOS classification numbers. Copies of the MOS classification scheme are available to authors on request.

\section{Copyright}

The material in this BULLETIN may be quoted in full or in part with due acknowledgement of the source. 
The BULLETIN of the Australian Mathematical Society is published for the Society by

The University of Queensland Press,

St Lucia, Queensland 4067,

Australia,

and printed by

Watson Ferguson \& Co.

Brisbane, Queensland 4101,

Australia. 